\title{
Performance of osteoporosis self-assessment tool in detecting low bone mineral density in menopausal women
}

\author{
Ignatio Rika Haryono* and Nawanto Agung Prastowo*
}

\begin{abstract}
\section{BACKGROUND}

The osteoporosis self-assessment tool (OST) is a simple screening tool to assess risk of osteoporosis and to select high risk women for dual-energy $\mathrm{x}$-ray absorptiometry (DXA) examination. This study aimed to evaluate OST performance in detecting low bone mineral density (BMD) in menopausal women.
\end{abstract}

\section{METHODS}

A cross-sectional study involving 60 menopausal women aged 50-65 years. The OST score was calculated from: [weight $(\mathrm{kg})-$ age $(\mathrm{yr})] \times 0.2$. Subjects were classified by OST score into low risk (OST $\geq 2)$ and high risk (OST< 2) groups. BMD was determined by DXA at 3 bone locations (L1-L4, femoral neck, and total hip). DXA T-scores were categorized into: normal BMD (T-score $>-1$ ) and low BMD (T-score $\leq-1$ ). Independent t-test was used to compare subject characteristics between OST groups. Diagnostic performance of OST was evaluated by measuring sensitivity, specificity, positive \& negative predictive value (PPV, NPV), positive \& negative likelihood ratio (PLR, NLR) and receiver-operating characteristic (ROC). Significance was set at $\mathrm{p}<0.05$.

\section{RESULTS}

Subject characteristics and BMD between groups were significantly different $(\mathrm{p}<0.05)$. Most subjects $(44 / 73.3 \%)$ had high risk of low BMD $(\mathrm{OST}<2)$. Low BMD (T score $\leq-1)$ was found in 43 subjects $(71.7 \%)$ at L1-L4, 41 subjects $(68.3 \%)$ at femoral neck, and 37 subjects $(61.7 \%)$ at total hip. Diagnostic performance of OST was significant at total hip BMD (sensitivity=0.946, $\mathrm{AUC}=0.777$ ).

\section{CONCLUSION}

We conclude that use of the OST score in menopausal women is effective and has adequate sensitivity and specificity. The highest diagnostic performance of OST is on total hip BMD.
*Department of Physiology,

Faculty of Medicine, Indonesia

Catholic University of Atma Jaya,

Jakarta, Indonesia

\section{Correspondence:}

Nawanto Agung Prastowo

Department of Physiology,

Faculty of Medicine,

Catholic University of Atma Jaya,

Pluit Raya street no 2, North Jakarta, Indonesia

Phone: +62216694366

Mobile: +62813 17477849

Fax: +6221 6606123

Email: nawanto2005@yahoo.co.id

Date of first submission, January 15, 2017 Date of final revised submission, August 7, 2017

Date of acceptance, August 9, 2017

This open access article is distributed under a Creative Commons AttributionNon Commercial-Share Alike 4.0 International License

Keywords: Bone mass, menopausal women, simple screening tools 


\section{INTRODUCTION}

Reduced bone mineral density, in the form of osteopenia or osteoporosis, frequently occurs in menopausal women. The prevalence of osteoporosis in menopausal women is up to $35.5 \%-44 \%,{ }^{(1,2)}$ and differs according to the location of the bones. In Indonesia the prevalence of osteopenia is highest at the femoral neck (45.8\%) and lowest at the distal radius (23.2\%), whereas the prevalence of osteoporosis is highest at the distal radius $(30 \%)$ and lowest at the femoral neck $(4.9 \%){ }^{(3)}$

Bone mineral density is associated with several risk factors, i.e. age, menopause, body weight, and body mass index (BMI). The majority of studies show a correlation of body weight, BMI, and age with bone mineral density. ${ }^{(4,5)}$ Elderly females with low body weight and BMI have lower bone mass. Another risk factor is socio-economic status. Osteoporosis is more frequent in females of lower economic status. $^{(6,7)}$

To find patients with newly acquired osteoporosis in Indonesia is not easy because of the still limited access to dual-energy $x$-ray absorptiometry (DXA). There are several factors limiting access DXA examination i.e. the relatively high cost of the examination, particularly for community groups with low economic status, the limited number of hospitals possessing DXA equipment, their location in large cities only, and the relatively great distance to these hospitals. It has been estimated that there are only 65 hospitals in Indonesia that possess DXA equipment. With the total size of the population of up to 250 million, the ratio of the number of the equipment to the population is less than 0.1 per million population.

The limited access to DXA examination results in the actual number of patients with osteoporosis being much larger than reported by the studies. In addition, there should be a selection for females with low bone mineral density for DXA examination. Several tools have been developed for evaluating the individual risk for osteoporosis that can be used for screening for DXA examination. The most frequent risk factors used in those tools are among others body weight, age, use of estrogens, and fractures. ${ }^{(8-10)}$ One of the most easily used tools that nevertheless has relatively high sensitivity (up to $90 \%$ ) is the osteoporosis self-assessment tool (OST). ${ }^{(11)}$

The osteoporosis screening tools take only body weight and age into account. ${ }^{(8-10)}$ There are several other tools that incorporate more risk factors, eg. the Simple Calculated Osteoporosis Risk Estimation (SCORE), Osteoporosis Risk Assessment Instrument (ORAI), Osteoporosis Index of Risk (OSIRIS), and WHO Fracture Risk Assessment (FRAX). In addition to body weight and age, these tools also incorporate several other risk factors, e.g. height, gender, ethnicity, and use of hormones. FRAX is the tool comprising the highest number of risk factors of up to 11 items. In spite of this, both meta-analytic studies and systematic reviews have shown that the sensitivity of these tools is not higher than or equal to that of OST. ${ }^{(11,12)}$ Furthermore, the performance of OST does not show consistent results, its sensitivity being higher than its specificity or vice versa. ${ }^{(13)}$

The present study was carried out to evaluate the performance of OST in a more specific manner i.e. by measuring the BMD of the bones according to location. Referrals for DXA examination generally come from clinics or hospitals. In the present study referrals for DXA examination were obtained by directly visiting the community groups without access to DXA examination, so as to obtain data from a valid number of patients with low bone mass.

\section{METHODS}

\section{Design of the study}

This study of cross-sectional design was carried out at 3 posyandu (integrated health care posts) in Tanah Merah and Luar Batang villages, North Jakarta, and in Cengkareng, West Jakarta from August 2014-January 2015. 


\section{Subjects of the study}

The subjects were 60 menopausal women aged 50-65 years who were members of an elderly group under the guidance of the Faculty of Medicine, Indonesia Catholic University of Atma Jaya, Jakarta. The sample size was determined using the formula for area-under-the curve (AUC) diagnostics i.e.:

$$
\mathrm{n}=\left[\frac{\mathrm{Z} \alpha \sqrt{2 \mathrm{~V}_{1}+\mathrm{Z} \beta \sqrt{\mathrm{V}_{1}+\mathrm{V}_{2}}}}{\mathrm{AUC}_{1}-\mathrm{AUC}_{2}}\right]^{2}
$$

where $\mathrm{Z} \alpha=1.64, \mathrm{Z} \beta=1.28, \mathrm{AUC} 1=0.7$, AUC2 $=0.8$. With an estimated number of $10 \%$ drop-outs, the total sample size required was around 70 . The sample selection flow may be seen in Figure 1. From 112 subjects, 30 subjects did not meet the inclusion and exclusion criteria and 22 subjects did not agree to undergo BMD examination, for a variety of reasons, such as having no time and being afraid of the side effects of the examination. The inclusion criteria were menopausal women aged 50-65 years, having attended the posyandu for 3 months consecutively, and having experienced menopause for 12 months or more. The exclusion criteria were smoking, being under steroid and hormonal treatment, consuming vitamin $\mathrm{D}$ and/or calcium supplements, having experienced fractures, and suffering from chronic disease. The inclusion and exclusion criteria, and demographic data were obtained through questionnaire-based interviews.

\section{Measurements}

Anthropometric measurements were performed in the service ward of each posyandu by a physician. Body weight was determined on the minimally clothed subjects, using SECA digital portable scales (SECA, Germany) with an accuracy of $0.1 \mathrm{~kg}$. Height was measured in the Frankfort position without footwear by means of a wall mounted stadiometer with an accuracy of $0.5 \mathrm{~cm}$. Body mass index (BMI) was determined by dividing the weight (in kilograms) by the square of the height (in meters) and expressed in $\mathrm{kg} / \mathrm{m}^{2}$.
The OST score was calculated with the formula: $0.2 \times$ [body weight (in kilograms) - age (in years)]. For example, a female person aged 50 years and weighing $65 \mathrm{~kg}$, has an OST score of $0.2(65-50)=3$. The OST scores were categorized with the cut-off value of 2; the BMD was normal if the OST score was $\geq 2$, and low if the OST score was $<2$. $^{(8,11,12)}$

\section{BMD examination}

BMD examination was performed in Siaga Hospital, South Jakarta, using standard DXA equipment (Lunar Prodigy DF+301251, GE Healthcare, USA). Examination and reading of the results was performed by a radiologist. The locations of the bones to be examined were according to the recommendations of the International Society for Clinical Densitometry, i.e. the vertebral column (L1-L4), left femoral bone (femoral neck), and total hip. ${ }^{(14)}$ The BMD examination yielded the BMD $\left(\mathrm{g} / \mathrm{cm}^{2}\right)$ and $\mathrm{T}$ scores. The T-score was used as a criterion for determining the BMD classification according to WHO standards, i.e. osteopenia if T-score between between $(-2.5)-(-1.0)$ and osteoporosis if T-score $<-2.5 .^{(15)}$ For statistical analysis the subjects were grouped according to the T-score, with a cut-off of -1 ; BMD was low if T-score $\leq$ 0.1 , and BMD normal if T-score $>-0.1$.

\section{Statistical analysis}

Numerical data were expressed as mean (standard deviation) and categorical data were expressed as values and percentages. The unpaired-t test was used for comparison of the mean between the low-risk group (OST >-1) and the moderate-high risk groups $(\mathrm{OST}<2)$. Evaluation of the OST performance was by calculating the sensitivity, specificity, positive likelihood ratio (PLR), negative likelihood ratio (NLR) and area under the ROC curve (area under the curve-AUC). The positive likelihood ratio is the probability of a positive OST in subjects with low BMD in comparison with subjects with normal BMD, whereas NLR is the probability of a negative OST in subjects with normal BMD 
Table 1. Comparison of subject characteristics and BMD between normal and at risk groups

\begin{tabular}{lccc}
\hline & $\begin{array}{c}\text { Normal OST } \\
(\mathbf{N}=\mathbf{1 6})\end{array}$ & $\begin{array}{c}\text { Low OST } \\
(\mathbf{N}=\mathbf{4 4})\end{array}$ & p value \\
\hline Age (years) & $53.87 \pm 4.38$ & $59.37 \pm 4.87$ & 0.000 \\
Age at menopause (years) & $52.06 \pm 3.60$ & $54.39 \pm 2.07$ & 0.003 \\
Duration of menopause (years) & $1.81 \pm 1.76$ & $4.99 \pm 3.71$ & 0.002 \\
Body weight $(\mathrm{kg})$ & $69.02 \pm 5.46$ & $53.18 \pm 6.56$ & 0.000 \\
BMI $\left(\mathrm{kg} / \mathrm{m}^{2}\right)$ & $29.74 \pm 2.16$ & $23.97 \pm 3.03$ & 0.000 \\
BMD, lumbar spine $(\mathrm{L} 1-\mathrm{L} 4)\left(\mathrm{g} / \mathrm{cm}^{2}\right)$ & $1.00 \pm 0.13$ & $0.88 \pm 0.15$ & 0.006 \\
BMD, femoral neck $\left(\mathrm{g} / \mathrm{cm}^{2}\right)$ & $0.86 \pm 0.11$ & $0.71 \pm 0.14$ & 0.000 \\
BMD, trochanter $\left(\mathrm{g} / \mathrm{cm}^{2}\right)$ & $0.73 \pm 0.11$ & $0.60 \pm 0.11$ & 0.000 \\
BMD, total hip $\left(\mathrm{g} / \mathrm{cm}^{2}\right)$ & $0.93 \pm 0.11$ & $0.77 \pm 0.12$ & 0.000 \\
& Normal BMD & Low BMD & \\
BMD, lumbar spine $(\mathrm{L} 1-14)$ & $17(28.3 \%)$ & $43(71.7 \%)$ & \\
BMD, femoral neck & $19(31.7 \%)$ & $41(68.3 \%)$ & \\
BMD, trochanter & $32(53.3 \%)$ & $28(46.7 \%)$ & \\
BMD, total hip & $23(38.3 \%)$ & $37(61.7 \%)$ & \\
\hline
\end{tabular}

$\mathrm{BMD}=$ bone mineral density; OST= osteoporosis self-assessment tool

as compared to subjects with low BMD. The sensitivity, specificity, PLR, and NPR are considered to be good if the sensitivity and specificity is up to $90 \%$ or more, the PLR more than 10 and the NLR less than 0.1. The AUC value for diagnostic ability is considered to be sufficiently good if it is $\geq 0.700$. The significance level was determined at $\mathrm{p}<0.05$. Statistical analysis was performed with SPSS version 17.0 for Windows (SPSS Inc., Chicago, Il.,USA).

\section{Ethical clearance}

Ethical clearance was granted by the ethics committee of the Faculty of Medicine, Unversity of Indonesia and Cipto Mangunkusumo Hospital (679/UN2.F1/ETIK/2014). The subjects provided written and signed informed consent. The identity of the subjects was kept confidential and used only for the purpose of the study.

\section{RESULTS}

A total of 60 subjects met the inclusion and exclusion criteria and agreed to undergo DXA examination. The majority of the subjects (44 or $73.3 \%$ ) were at high risk for low bone mass (OST score <2). Subject characteristics and BMD between the two OST groups were significantly different $(\mathrm{p}<0.05)$. In the low risk group, mean BMD at 4 bone locations was in the normal category, whereas in the high risk group, mean BMD was in the categories of osteopenia (femoral neck, trochanter, and total hip) and osteoporosis (lumbar spine). Low BMD ( $\mathrm{T}$ score $\leq-1$ ) was most frequent in the lumbar spine (Table 1).

Table 2 shows the OST performance in evaluating low BMD risk in post-menopausal women aged 50-65 years. OST sensitivity was

Table 2. Validity of OST at each bone location

\begin{tabular}{lcccc}
\hline & $\begin{array}{c}\text { Sensitivity } \\
(\mathbf{9 5 \%} \text { CI) }\end{array}$ & $\begin{array}{c}\text { Specificity } \\
\mathbf{( 9 5 \%} \text { CI) }\end{array}$ & $\begin{array}{c}\text { PLR } \\
(\mathbf{9 5 \%} \text { CI) }\end{array}$ & $\begin{array}{c}\text { NLR } \\
(\mathbf{9 5 \%} \text { CI) }\end{array}$ \\
\hline BMD, lumbar spine (L1-L4) & $81.4(66.6-91.6)$ & $47.1(22.9-72.2)$ & $1.54(1.0-2.5)$ & $0.39(0.2-0.9)$ \\
BMD, femoral neck & $85.4(70.8-94.4)$ & $52.6(28.8-75.6)$ & $1.81(1.2-2.9)$ & $0.28(0.1-0.6)$ \\
BMD, trochanter & $92.9(76.5-99.1)$ & $43.7(26.4-62.3)$ & $1.65(1.2-2.3)$ & $0.16(0.0-0.7)$ \\
BMD, total hip & $94.6(81.8-99.3)$ & $60.9(38.5-80.3)$ & $2.42(1.4-4.1)$ & $0.09(0.0-0.4)$ \\
\hline
\end{tabular}

$\mathrm{BMD}=$ bone mineral density; $\mathrm{CI}=$ confidence interval; $\mathrm{NLR}=$ negative likelihood ratio; $\mathrm{PLR}=$ positive likelihood ratio 
Table 3. Area under the receiver operating characteristic curve

\begin{tabular}{lcc}
\hline & AUC & 95\% CI \\
\hline BMD, lumbar spine & $64.2 \%$ & $0.479-0.806$ \\
BMD, femoral neck & $69.0 \%$ & $0.536-0.844$ \\
BMD, trochanter & $68.3 \%$ & $0.548-0.819$ \\
BMD, total hip & $77.7 \%$ & $0.644-0.911$ \\
\hline
\end{tabular}

$\mathrm{AUC}=$ area under the receiver operating curve $\mathrm{BMD}=$ bone mineral density; $\mathrm{CI}=$ confidence interval

sufficiently good for the BMD values of the trochanter and total hip. OST specificity was sufficiently good for total hip BMD. The PLR and NLR values were low at all BMD locations. According to the area under the curve (AUC), OST has lower diagnostic value in the BMD of the lumbar spine, trochanter and femoral neck. The diagnostic value of OST was significant only for total hip BMD (Table 3).

\section{DISCUSSION}

The results of the present study show that OST functions as a fairly good tool for evaluating low BMD risk in menopausal women aged 50-65 years. OST performance showed a sensitivity in the range between $81-95 \%$, specificity $47-61 \%$, PLR and NLR in the range between 1.54-2.42 and 0.09-0.39. However, according to the ROC area, OST performance was only significantly different for total hip BMD (AUC=77.7\%).

These study results differed from those of a study in Thailand, which showed OST sensitivity and specificity of $36-48 \%$ and $71-$ $75 \%$, respectively. The subjects of the Thai study were menopausal women aged 45-87 years and the OST cut off value was $-1 .{ }^{(13)}$ Similar results were found in Argentinian studies, in which the subjects were menopausal women aged 50 years and older and the OST cut off score was 2 . The results showed sensitivity and specificity values of $84 \%$ and $44 \%$, respectively. ${ }^{(16)}$ The sensitivity and specificity may have been influenced by the younger age of the subjects and the lower cut off value. In subjects less than 50 years old, the bone mass may not have decreased to a great extent, so that the majority of the subjects still had normal BMD values. Negative OST scores may decrease the number of subjects who fall in the high risk category because the age of the subjects should be greater than their body weight or their body weight should be less than their age.

The OST performance differed according to bone location. The results of the present study showed the highest sensitivity and specificity for total hip. Several previous studies have found similar results. A study in Malaysia on menopausal subjects measured the OST performance in the proximal femur and lumbar spine, and found that the sensitivity in the proximal femur was higher ( $87.5 \%$ vs $47.8 \%) .{ }^{(17)}$ The aforementoned study in Thailand also reported a higher sensitivity for BMD of the femur $(40.6 \%$ vs $36.2 \%) .^{(13)}$ Total hip in the present study comprised the femoral neck and trochanter, which are also parts of the proximal femur. The OST sensitivity was highest for BMD of the proximal femur or total hip because in these regions the cortical bone thinned out more rapidly as a result of aging and underwent fractures. ${ }^{(18)}$

The number of subjects with low BMD in the present study was substantial. According to bone location, low BMD was most frequent in the lumbar spine. Similar results were obtained in several previous studies. ${ }^{(13,17,18)}$ However, the percentage of subjects with low BMD in the present study was relatively high as compared with the aforementioned studies, and even with a previous study in Indonesia. ${ }^{(3)}$ The difference may be the result of differences in $\mathrm{T}$ score cut off values, subject characteristics, type of DXA equipment and their operators.

In addition to OST, there are several screening tools that are used for evaluating the risk of low bone mass and fractures. These screening tools have been developed by incorporating other risk factors besides age and body weight. The Fracture Risk Assessment Tool (FRAX) incorporates the greatest number of risk factors, among others gender, use of estrogens, 
glucocorticoids, smoking, alcohol, history of fractures, and rheumatoid arthritis. The Simple Calculated Osteoporosis Risk Estimation (SCORE) incorporates the factors of race, history of fractures, use of estrogens and rheumatoid arthritis. The Osteoporosis Risk Assessment Instrument (ORAI) incorporates only the use of estrogens. ${ }^{\left({ }^{8} 10\right)}$ Several studies have been conducted to compare the efficacy of these tools. The study by Pecina et al. ${ }^{(8)}$ showed that the sensitivity and AUC were $36 \%$ and $55 \%$ respectively for FRAX, 74\% and 58\% for SCORE, $56 \%$ and $63 \%$ for OST, and $52 \%$ and $60 \%$ for ORAI. ${ }^{(8)}$ The study by Rubin et al, ${ }^{(10)}$ comparing FRAX and other tools, found that the performance of FRAX and the other tools were not much different, with the AUC ranging between $70.3 \%-72.2 \%{ }^{(10)}$ These studies have demonstrated that the increase in added risk factors in these tools did not add to the performance in evaluating the risk of low bone mass. Age and body weight are the most influential risk factors for osteoporosis ${ }^{(4,5,19)}$ so that the other factors added to these screening tools could not much increase their performance.

Body weight is considered to have a protective effect on osteoporosis. The influence of body weight on bone mass is caused by physiological load, mechanical load, and endocrine effects. ${ }^{(20-2)}$ However, the protective effect of body weight on reduced bone mass has to date been questioned. The study by Greco et al ${ }^{(23)}$ on overweight and obese subjects showed that $33 \%$ of female subjects and $45 \%$ of male subjects possess lower BMD. ${ }^{(23)}$ It is thought that at a certain degree of obesity, because of the influence of interleukin and tumor necrosis factor (TNF), the adipocytes may change into osteoclasts that play a role in bone resorpstion and reduced bone mass. ${ }^{(20-22)}$

The present study has several limitations. First, there are no data on several risk factors that affect bone formation and bone mass, such as the level of physical activity and exposure to sunlight. Second, the subjects comprised a relatively homogenous group with regard to ethnicity and social status, which are risk factors for low bone mass.

The screening tools for evaluating the risk for osteoporosis are important for the efficiency and efficacy of DXA examinations, which are still costly and unaffordable. There have been many studies on the performance of the tools in detecting the risk of low bone mass. The simple screening tools showed an identical or greater performance as compared with the more complex tools. The use of OST for screening of risk groups is very easy so that it can be carried out not only by medical personnel but also by trained health cadres. In addition, there are many different ethnic groups and socio-economic classes in Indonesia. There is a need for studies on elderly groups in each province and of various socio-economic classes to find the prevalence of low BMD and simultaneously test the performance of OST in subjects of different ethnic and socio-economic groups.

\section{CONCLUSION}

This study demonstrated that use of the OST score in postmenopausal women was effective and had adequate sensitivity and specificity.

\section{CONFLICT OF INTEREST}

The authors declare that there was no conflict of interests in any form and with any parties whatsoever.

\section{ACKNOWLEDGMENT}

The authors express their gratitude to Heydi MD, Nelson MD, Alfian Prasetyo MD, and Alice Angelina MD for technical assistance. Thanks are also due to Ms. Chamimah, Ms. Oon, and Ms. Pujawati for recruitment of the subjects. We also thank the Faculty Medicine, Indonesia Catholic University of Atma Jaya for the funding of this study. 


\section{CONTRIBUTORS}

NAP and RH contributed to drafting and revision of the manuscript. NAP contributed to the study design and data collection. RH contributed to the statistical analysis and interpretation, All authors read and approved the manuscript.

\section{REFERENCES}

1. Choi YJ, Oh HJ, Kim DJ, et al. The prevalence of osteoporosis in Korean adults aged 50 years or older and the higher diagnosis rates in women who were beneficiaries of a national screening program: The Korea National Health and Nutrition Examination Survey 2008-2009. J Bone Miner Res 2012;27:1879-86.

2. Wright NC, Looker AC, Saag KG, et al. The recent prevalence of osteoporosis and low bone mass in the United States based on bone mineral density at the femoral neck or lumbar spine. J Bone Miner Res 2014; 29:2520-6.

3. Meiyanti. Epidemiology of osteoporosis in postmenopausal women aged 47 to 60 years. Univ Med 2010;29:169-76.

4. Montazerifar F, Karajibani M, Alamian S, et al. Age, weight, and body mass index effect on bone mineral density in postmenopausal women. Health Scope 2014;3:e14075. DOI: 10.17795/ jhealthscope-14075.

5. Rexhepi S, Bahtiri E, Rexhepi M, et al. Association of body weight and body mass index with bone mineral density in women and men from Kosovo. Mater Sociomed 2015;27:259-62.

6. Navarro MC, Sosa M, Saavedra P, et al. Poverty is a risk factor for osteoporotic fractures. Osteoporosis Int 2009;20:393-8.

7. Romero GT, Rodriguez N, Santana S, et al. Prevalence of osteoporosis, vertebral fractures and hypovitaminosis D in postmenopausal women living in a rural environment. Maturitas 2014;77:282-6.

8. Pecina JL, Romanovsky L, Merry SP, et al. Comparison of clinical risk tools for predicting osteoporosis in women ages 50-64. J Am Board Fam Med 2016;29:233-9.

9. Ahmadzadeh A, Emam M, Rajaei A, et al. Comparison of three different osteoporosis risk assessment tools: ORAI (osteoporosis risk assessment instrument), SCORE (simple calculated osteoporosis risk estimation), and
OST (osteoporosis self-assessment tool). Med J Islam Repub Iran 2014;28:94.

10. Rubin KH, Abrahamsen B, Friis-Holmberg T, et al. Comparison of different screening tools (FRAX ${ }^{\circledR}$, OST, ORAI, OSIRIS, SCORE and age alone) to identify women with increased risk of fracture: a population-based prospective study. Bone 2013;56:16-22.

11. Nayak S, Edwards DL, Saleh AA, et al. Systematic review and meta-analysis of the performance of clinical risk assessment instruments for screening for osteoporosis or low bone density. Osteoporosis Int 2015;26:1543-54.

12. Rubin KH, Friis-Holmberg T, Hermann AP, et al. Risk assessment tools to identify women with increased risk of osteoporotic fracture: complexity or simplicity? A systematic review. J Bone Miner Res 2013;28:1701-17.

13. Chaovisitsaree S, Namwongprom SN, Morakote $\mathrm{N}$, et al. Comparison of osteoporosis selfassessment tool for Asian (OSTA) and standard assessment in menopause clinic, Chiang Mai. J Med Assoc Thai 2007;90:420-5.

14. Hans DB, Shepherd JA, Schwartz EN, et al. Peripheral dual-energy X-ray absorptiometry in the management of osteoporosis: the 2007 ISCD Official Positions. J Clin Densitometry 2008;11: 188-206.

15. Siris ES, Adler R, Bilezikian J, et al. The clinical diagnosis of osteoporosis: a position statement from the National Bone Health Alliance Working Group. Osteoporos Int 2014;25:1439-43.

16. Saraví FD. Osteoporosis self-assessment tool performance in a large sample of postmenopausal women of Mendoza, Argentina. J Osteoporos 2013; http://dx.doi.org/10.1155/2013/150154.

17. Muslim DAJ, Mohd EF, Sallehudin AY, et al. Performance of osteoporosis self-assessment tool for Asian (OSTA) for primary osteoporosis in post-menopausal Malay women. Malay Orthop J 2012;6:35-9.

18. Chen H, Zhou X, Fujita $\mathrm{H}$ et al. Age-related changes in trabecular and cortical bone microstructure. Int J Endocrinol 2013; http:// dx.doi.org/10.1155/2013/213234.

19. Morin S, Tsang JF, Leslie WD. Weight and body mass index predict bone mineral density and fracture in women aged 40 to 59 years. Osteoporosis Int 2009;20:363-70.

20. Cao JJ. Effects of obesity on bone metabolism. J Orthop Surg Res 2011;6:30. DOI:10.1186/1749799X-6-30.

21. Liu PY, Ilich JZ, Brummel-Smith K, et al. New insight into fat, muscle, and bone relationship 
in women: determining the threshold at which body fat assumes negative relationship with bone mineral density. Int J Prev Med 2014;5:152-63.

22. Migliaccio S, Greco EA, Fornari R, et al. Is obesity in women protective against osteoporosis? Diabetes Metab Syndr Obes 2011; $4: 273-82$.
23. Greco EA, Fornari R, Rossi F, et al. Is obesity protective for osteoporosis? Evaluation of bone mineral density in individuals with high body mass index. Int J Clin Prac 2010;64:817-20. 